\title{
Metabolic Syndrome and Mental Health in the Time of Covid-19 Pandemic
}

\section{G. Stefkova (Gabriela Stefkova), M. Zamboriova (Maria Zamboriova)}

Pavol Jozef Safarik University, Faculty of Medicine, Department of Nursing

Care, Kosice, SK.

\section{E-mail address:}

gabriela.stefkova@upjs.sk

\section{Reprint address:}

Gabriela Stefkova

Pavol Jozef Safarik University in Kosice

Faculty of Medicine

Department of Nursing Care

Kosice

Slovakia

Source: Clinical Social Work and Health Intervention

Volume: 12

Issue: 5

Pages: $15-21$

Cited references: 40

\section{Reviewers:}

Gabriela Lezcano

University of California, San Francisco, USA

Vitalis Okoth Odero

Catholic university of Eastern Africa, Nairobi, KE

\section{Keywords:}

COVID-19 Pandemic. Metabolic Syndrome. Mental Illnesses.

\section{Publisher:}

International Society of Applied Preventive Medicine i-gap

CSWHI 2021; 12(5): 15 - 21; DOI: 10.22359/cswhi_12_5_02 (C) Clinical Social Work and Health Intervention

\section{Abstract:}

Introduction. At the end of 2019, China was hit by a disease with pandemic potential. It was a new coronavirus, also called COVID-19 (coronavirus disease). In March 2020, the World Health Organization (WHO) declared the situation a pandemic. Those most at risk were people with metabolic syndrome, mentally ill and the elderly. Metabolic syndrome (MetS) and its components have become a monitored issue in the context of mental illnesses. The COVID-19 pandemic, metabolic syndrome, and mental health have become interrelated. The number of mental illnesses has grown exponentially around the world, having affected several age groups.

Methodology. A search and selection of articles from the online scientific database WOS through bibliometric analysis, using the keywords "COVID-19", "metabolic syndrome", 


\begin{abstract}
"mental illnesses" in the period from 2020 to 2021 to present the relationships between metabolic syndrome and mental illnesses during the COVID - 19 pandemic.

Conclusion. In the area of publications, the issue of depression during the COVID - 19 pandemic was the most watched topic. A higher incidence of metabolic syndrome or its components has been reported in patients suffering from mental illnesses.
\end{abstract}

\section{Introduction}

Within a few months, the COVID-19 pandemic has caused a global public health crisis with psychological and health consequences. The issue of the prevalence of metabolic syndrome and its components, along with mental illnesses, has grown in every age group and gender. Metabolic syndrome (MetS), also known as syndrome $\mathrm{X}$, chronic cardiovascular disease syndrome, and Reaven syndrome is a multisystem disorder (1). It is based on the pathophysiological knowledge of the cardiovascular consequences of insulin resistance and abdominal fat storage. The knowledge of the metabolic syndrome issue in the context of a pandemic currently applies not only to metabolically oriented internists, but to all physicians, from preventive cardiologists to psychiatrists. A correctly diagnosed metabolic syndrome in a high-risk patient with mental disorder will always be a warning to healthcare professionals. Treatment options for the metabolic syndrome in general, from regimen measures to surgery, are set. There is a very complex relationship between metabolic syndrome and mental health conditions (2). Mental health refers to cognitive, behavioural and emotional well-being. Before the coronavirus disease (COVID-19) pandemic, almost 1 billion people worldwide suffered from some mental disorder. About 50 million people suffered from dementia and about 250 million people from alcohol or drug use disorders. Approximately half of all mental disorders started at the age of early adulthood (3). Coronavirus disease has been shown to have direct and indirect effects on human mental health and is a risk factor for the development, exacerbation and relapse of the metabolic syndrome.

\section{Metabolic syndrome}

The genesis of the metabolic syndrome concept is complex due to the comorbidity of the disease. The first co-occurrence of high blood pres- sure, hyperglycaemia, and hyperuricemia was sufficient to diagnose MetS (4). Later, doctors correlated the waist / hip ratio with intra-abdominal fat. By that, they pointed to the metabolic complications of obesity, accompanied by a high ratio of waist circumference to hip circumference, which was specifically related to the amount of intra-abdominal fat (5). In the late 1980s, the definition of the metabolic syndrome was followed by the term 'deadly quartet', which consisted of the presence of obesity with a predominance of adipose tissue in the upper half of the body, hypertension, diabetes, and hypertriglyceridemia (6). A fundamental pathophysiological importance to the determination of MetS - already with the name "syndrome X" - was given by an American internist and endocrinologist Reaven (7). He placed emphasis on high cardiovascular risk and body fat distribution to determine the type of obesity (8). Visceral obesity has become an essential determinant of insulin resistance, leading to pathophysiological changes that lead to metabolic syndrome $(9,10,11)$. Naming MetS an "Insulin Resistance Syndrome" formerly "Syndrome X" has harmonized many years of research of risk factors for cardiovascular diseases, insulin resistance, and abdominal adipose tissue deposition. The predictor of the development of the metabolic syndrome was an increase in the level of insulin resistance, where visceral adiposity played an important role in the diagnosis of MetS (12). The first clinical definition of the metabolic syndrome was proposed in the late 1990s by the World Health Organization (13). The diagnosis of MetS determined a condition meeting the criteria for the metabolic syndrome or biochemical clinical criteria by the existence of a combination of three of the five or more factors present (16 in total), waist circumference, triglyceridemia, HDL-cholesterol, high blood pressure, and fasting blood glucose (Figure 1). This definition quickly became popular for its 
simplicity and is still the most widely used definition of the metabolic syndrome. The determination of the presence of metabolic syndrome as defined above does not require any special examination. An examination of glycemia, triacylglycerolemia, HDL-cholesterol and blood pressure are currently common practice in routine preventive examinations.

\section{Figure 1 metabolic syndrome causes}

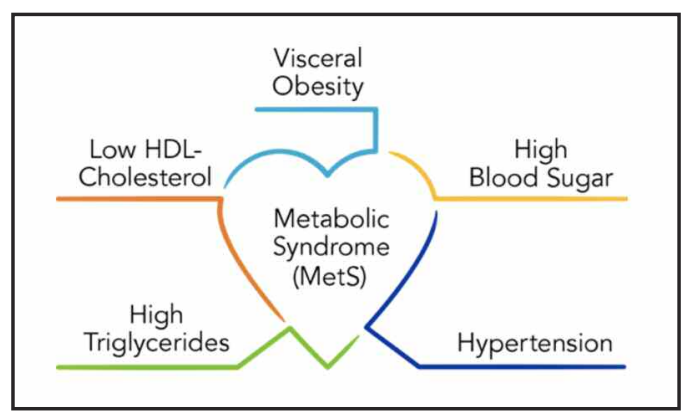

Source: https://www.metabolicsyndromecanada.ca/about-metabolic-syndrome

\section{Mental health}

Mental health care involves striking a balance between life activities and psychological flexibility. Mental illnesses have a number of health consequences, which often lead to a significant deterioration in the state of health and in the quality of patient's life (14). The World Health Organization (WHO, 2001) defines mental health as "a state of well-being in which the individual realizes his or her own abilities, can cope with the normal stresses of life, can work productively and fruitfully, and is able to make a contribution to his or her community". Mental health can be affected by personal (e.g. gender), social (e.g. social relations and economic status) and family (e.g. family connections) factors (15). Worldwide, depression is a common mental health problem and is a major cause of the overall global burden of diseases $(15,16)$. The impact of depression is dangerous, it affects the quality of life of an individual by reducing their social functions and ability to cope with common situations. The WHO's vision for mental health in the program (GPW13) for 2019-2023 is to achieve the highest levels of mental health and well-being for all people (17).

\section{Covid $\mathbf{- 1 9}$}

At the end of 2019, a new disease with pandemic potential appeared in China. It was a new coronavirus called coronavirus disease 2019 (COVID-19) (18). Later, in the first quarter of 2020, the World Health Organization declared the outbreak of the disease a pandemic, after the virus infected more than 381,000 people in 195 countries. COVID-19 is an infectious disease that is the third identified SARS-CoV-2 coronavirus causing serious disease in humans. The first was SARS$\mathrm{CoV}$, also from China, which caused a pandemic between 2002 and 2003. In 2012, there was MERS-CoV (middle east respiratory syndrome), the second coronavirus, causing severe acute respiratory syndrome $(19,20)$. As coronaviruses have bats as their natural hosts, COVID-19 is considered a zoonosis (21). More vulnerable to COVID - 19 have been people with comorbidities, the elderly, and the helping professions (22). Transmission of SARS-CoV-2 occurred by excretion of airway droplets or saliva into the nasal, oral, or conjunctival mucosa during speech, cough, or sneezing directly between the infected and susceptible individuals. It was also transmitted indirectly, through contaminated objects or surfaces. The incubation time in symptomatic cases ranged from 2 to 14 days, with an average of 5 days (22). The course of the disease varied depending on the individual immunological factors, age and existing comorbidities. In a mild form of the disease, the upper respiratory tract was affected, with the occurrence of fever, fatigue, myalgia, cough, odynophagia, runny nose and sneezing. Gastrointestinal symptoms were manifested by abdominal pain; vomiting, and diarrhoea have also been reported (23). More frequently the occurrence of severe acute respiratory syndrome has been observed in elderly patients with COVID-19 pneumonia and chronic diseases, e.g. type 2 diabetes, chronic obstructive pulmonary disease, systemic arterial hypertension, cardiovascular diseases (24).

In moderate COVID - 19 disease, the lower respiratory tract was affected, accompanied by pneumonia, fever, and cough. The determining criterion for the severity of the disorder was the presence or absence of hypoxia (25). COVID-19 affected all age groups; however, people over the age of 60 had the worst prognosis leading to death (26). At the time of the pandemic, measures were taken which led to social isolation, loss or risk of 
loss of income and livelihood, economic unrest, increased alcohol and drug use, intimate partners and family violence, reduced physical activity and intellectual stimulation and others (27). Many people feared a new infection, death or a possible loss of family members. Analyses of Covid-19 pandemic studies have shown that forced quarantine has led to feelings of confusion, anger, and post-traumatic stress disorder (28). The age group of 21-40 years (as opposed to people over the age of 65) has been more exposed to depressive experience due to future fear and economic problems associated with job loss (29).

\section{Methodology}

We have used WOS (Web of Science) as one of the online databases in the MyRa application to collect bibliometric data. In the online database, we selected the "search" option and entered keywords to obtain available publications related to COVID-19 in interaction with metabolic syndrome and mental health. We have limited the continuous updating of the database to search in the range of 2020 - 2021 with the following parameters: open access, area category: medicine, document type: full text / abstract, country of selection and language of documents: without restriction. We performed the method of bibliometric analysis according to the following procedure: to interact with COVID-19, we entered the terms "metabolic syndrome" and "mental health" into the search engine. At the time of data collection, we captured 143,682 articles on COVID-19 in the WOS database, on metabolic syndrome and mental health in the interaction with COVID-19, there were 1,537 publications in all areas of research. The database was created mostly by authors from the USA.

\section{Results}

\section{Metabolic syndrome, mental health and Covid - 19}

A review of selected publications showed that the COVID-19 pandemic has caused a global public health crisis with psychological and health consequences within a few months. Metabolic syndrome currently affects more than a billion people worldwide (3). In all patients diagnosed with metabolic syndrome, including hypertension, diabetes, cardiovascular disease, there has been a poor prognosis for coronavirus disease
(30). In most countries, epidemiological data have confirmed a dramatic increase in the prevalence of obesity at the time of the pandemic, especially in the young population. The reason was physical inactivity, poor eating habits, sedentary lifestyle (31, 32). Physical inactivity and obesity have also become increasingly important factors in mental illness (32). Discussions on whether mental illnesses are associated with stress, an inflammatory response, or a genetic predisposition are also being considered in the context of the metabolic syndrome in the field of psychiatry. The life expectancy for people suffering from psychotic illnesses before the pandemic was 1330 years shorter and the risk of death was 2-3 times higher due to somatic illnesses compared to the general population (33). Scientific articles on the most common somatic disorders and diseases in people with mental illnesses have confirmed an increased prevalence of obesity, metabolic syndrome (MetS), type 2 diabetes and cardiovascular diseases during the COVID - 19 pandemic. The incidence of overweight or obesity was more common in individuals with mental illness than in individuals without the disease (34). Figure 2 presents the most common terms used in many publications in relation to the impact of the COVID - 19 pandemic on mental health (35).

Mental health disorders are encountered by people with various time constraints and mental disabilities throughout their lives (14). We can already prove today that in the initial phase of the outbreak of COVID - 19 there was a deterioration in mental state, in particular higher levels of stress, anxiety, depression and post - traumatic symptoms in females, students, people with other pre - existing conditions, people with greater perception of the risk of the disease, people with higher rate of rumination, social tension and less social support (36). Higher rates of violence, selfharm, and suicidal ideation were also reported during the first month of the pandemic $(29,37$, 38 ). Studies have reported higher rates of depressive experience in people aged 21-40 (as opposed to people over 65) due to future concerns and economic problems, especially job loss. A higher level of anxiety was caused by the "proximity of the pandemic", a condition in which a person personally knew someone infected with a coronavirus, whether it was a family member, friend or acquaintance $(32,39)$. Researches recorded 
a high rate of depression and suffering symptoms among health professionals in the so-called front - line workers working with COVID - 19 patients (40). The impact of quarantine measures has led to feelings of confusion, anger, and post-traumatic stress disorder in people travelling for work $(27,28)$. Patients with severe mental illnesses, especially with schizophrenia and chronic mood disorders, have shown a higher prevalence of the metabolic syndrome or its components compared to a general population in several countries (27).

\section{Conclusion}

Risk factors for metabolic syndrome and mental illnesses will continue to invalidate and shorten life expectancy. However, it is too early to say whether the impact of the COVID - 19 pandemic on mental health creates an overall pattern of the metabolic syndrome. Due to the prevalence of metabolic syndrome in patients with mental illnesses, basic and regular medical examinations and the cooperation of doctors from psychiatric outpatient clinics should be a standard part of the ongoing health assessment. Patient education and adequate control of psychiatric symptoms will also be important parameters in achieving long-term treatment success. Regular monitoring of all MetS factors is the cornerstone of the early detection of the disease as well as of its treatment itself. In the context of the COVID - 19 pandemic, future research could focus on the concept of genetic predisposition to the development of MetS with mental illness.

\section{Declaration on Interest}

The authors declare that they have no conflict of interest.

\section{References}

1. CORNIER M, DABELEA D, HERNANDEZ T, LINDSTROM R, STEIG A, STOB N, et al. (2008) The metabolic syndrome. Endocr Rev. 2008; 29:777-822.

2. RÄIKKÖNEN K, MATTHEWS KA, KULLER LH (2002) The relationship between psychological risk attributes and the metabolic syndrome in healthy women: antecedent or consequence? Metabolism. 2002; 51:1573-1577.

3. MENTAL HEALTH PREPAREDNESS AND RESPONSE FOR THE COVID-19 PANDEMIC (2020). Report by the DirectorGeneral. WHO. [online]. 2020, [cit.2020-0504]. Available online: https://apps.who.int/gb/ ebwha/pdf_files/EB148/B148_20-en.pdf.

4. SUCHARDA P (2010) Metabolic syndrome,

Figure 2 A map visualization of the most common terms used in articles on COVID -19 and depression.

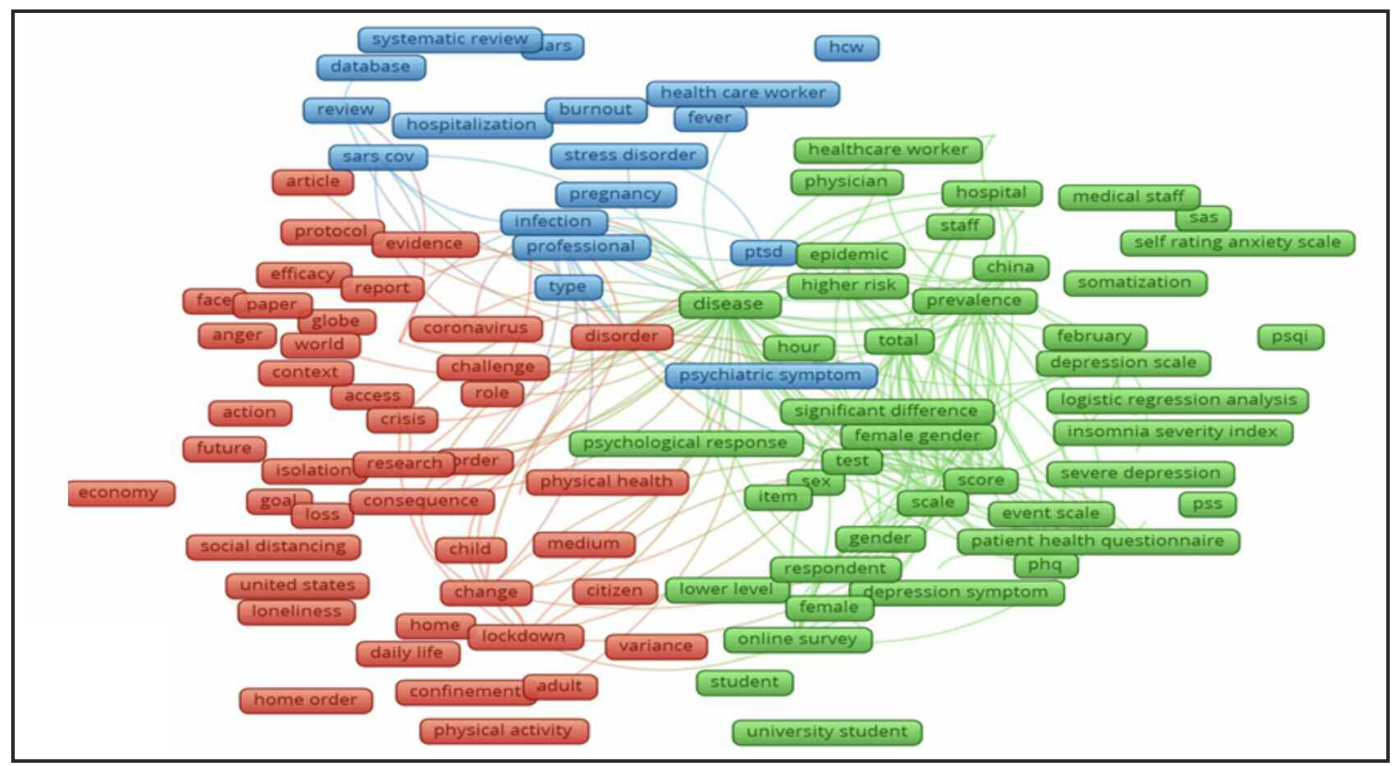

Source: Al-Jabi, 2021 
its diagnosis and treatment options. Med. praxi. 2010; 7(3):111- 114.

5. PEIRIS AN, SOTHMANN MS, AND HENNES MI, et al. (1989) Relative contribution of obesity and body fat distribution to alterations in glucose insulin homeostasis: predictive values of selected indices in premenopausal women. Am J Clin Nutr. 1989; 49:758-764.

6. TKAC I, KLIMES I, KRAHULEC B, MIKES Z, MURIN J, RASLOVA K (2005) Diagnosis and possibilities of therapeutic effect of metabolic syndrome. Internal Medicine. 2005; 5:239-242.

7. GALAJDA P (2007) Metabolic syndrome, cardiovascular and metabolic risks. Via practica. 2007; 4 (S4)5-9.

8. ISOMAA B, ALMGREN P, AND TUOMI T et al. (2001) Cardiovascular morbidity and mortality associated with the metabolic syndrome. Diabetes Care. 2001; 24:683-689.

9. GOLDSTEIN BJ (2002) Insulin resistance as the core defect in type 2 diabetes mellitus. Am J Cardiol. 2002; 90:3-10.

10. TOALSON P, SAEEDUDDIN A, HARDY T, GARY KABINOFF G (2004) The Metabolic Syndrome in Patients With Severe Mental Illnesses. Prim Care Companion. J Clin Psychiatry. 2004; 6(4): 152-158.

11. LOPUSZANSKA UJ, SKORZYNSKADZIDUSZKO K, LUPA-ZATWARNICKA K, MAKARA-STUDZINSKA M (2014) Mental illness and metabolic syndrome - a literature review. Annals of Agricultural and Environmental Medicine. 2014; 21(4): 815-821.

12. FACCHINI FS, HUA N, AND ABBASI F, et al.(2001) Insulin resistance as a predictor of age-related diseases. J Clin Endocrinol Metab. 2001; 86:3574-3578.

13. Metabolic syndrome is a health crisis hiding in plain sight. [online] Available online: https://www.metabolicsyndromecanada.ca/ab out-metabolic-syndrome.

14. The world health report 2001 Mental Health: New Understanding, New Hope". World Health Organization. [online]. 2020, [cit. 2020-05-04]. Available online: https:// www. who.int/whr/2001/en/whr01_en.pdf?ua=1.

15. HERRMAN H, SAXENA S, MOODIE R (2005). Promoting mental health: concepts, emerging evidence, practice: a report of the
World Health Organization, Department of Mental Health and Substance Abuse in collaboration with the Victorian Health Promotion Foundation and the University of Melbourne. World Health Organization.

16. WORLD HEALTH ORGANIZATION. Behavioural intervention shows promise for treating depression and anxiety in conflict-affected areas. Mental health.. [online]. 2020, [cit.2020-05-16]. Available online: http:// www.who.int/mental_health/management/de pression/en/.

17. THIRTEENTH GENERAL PROGRAMME OF WORK (GPW13): methods for impact measurement World Health Organization. [online]. 2020, [cit.2020-05-16]. Available online: https://cdn.who.int/media/docs/default-source/documents/about-us/thirteenthgeneral-programme/gpw13_methodology_ nov9_online-version $1 \mathrm{~b} 3170 \mathrm{f} 8-98 \mathrm{ea}-4 \mathrm{fcc}-$ aa3a-059ede7e51ad.pdf?sfvrsn=12dfeb0d $1 \&$ download=true 17 .

18. WORLD HEALTH ORGANIZATION. Maintaining essential health services:operational guidance for the COVID-19 context. Geneva: World Health Organization. [online]. 2020, [cit.2020-11-16]. Available online: https:// www.who.int/publications/i/ item/WHO-2019nCoV-essential-health--services-2020.119.

19. PETROSILLO N, VICECONTE G, ERGONUL O, IPPOLITO G, PETERSEN E (2020) COVID-19, SARS and MERS: are they closely related? Clin Microbiol Infect. 2020; 26: 729-734.

20. JEONG H, WOO H, SONG, Y. J, KI M, MIN J, CHO J, CHAE J.H. (2016) Mental health status of people isolated due to Middle East Respiratory Syndrome. Epidemiology and Health. 2016; vol.38, e2016048.

21. FUNG M, OTANI I, PHAM M, BABIK J (2021) Zoonotic coronavirus epidemics: Severe acute respiratory syndrome, Middle East respiratory syndrome, and coronavirus disease 2019. Ann Allergy Asthma Immunol. 2021; 126: 321.

22. ALBERTI A, SCHUELTER-TREVISOL B, MOEHLECKE ISER BETINE P, ELIANE TRAEBERT E et al. (2021) Obesity in people with diabetes in COVID-19 times: Important considerations and precautions to be taken. World J Clin Cases. 2021; 16; 9(20), p. 5358-5371. 
23. ISER BPM, SLIVA I, RAYMUNDO VT, POLETO MB, SCHUELTER-TREVISOL F, BOBINSKI F (2020) Suspected COVID-19 case definition: a narrative review of the most frequent signs and symptoms among confirmed cases. Epidemiol Serv Saude. 2020; 29: e2020233.

24. GRASSELLI G, ZANGRILLO A, ZANELLA A, ANTONELLI M, CABRINI L, CASTELLI A et al. (2020) COVID-19 Lombardy ICU Network. Baseline Characteristics and Outcomes of 1591 Patients Infected With SARS-CoV-2 Admitted to ICUs of the Lombardy Region, Italy. JAMA. 2020; 323: 1574-1581.

25. YUKI K, FUJIOGI M, KOUTSOGIANNAKI S. COVID-19 pathophysiology: A review. Clin Immunol. 2020; 215: 108427.

26. SCHUELTER-TREVISOL F, RAIMUNDO LJ, SOCCAS HD, ANTUNES AF, MOHR RLD, MARCON CEM, TREVISOL DJ. Assessment of patients with Covid-19 hospitalized in southern Santa Catarina. Rev Soc Bras Med Trop. 2020; 53: e20200579.

27. DZUKA J, KLUCAROVA Z, BABINCAK P (2021) Covid-19 in Slovakia: economic, social and psychological factors of subjective well-being and symptoms of depression during a pandemic. Czechoslovak Psychology. 2021; vol. LXV, no. 2, p. 125 145.

28. BROOKS SK, WEBSTER RK, SMITH LE, WOODLAND L, WESSELY S, GREENBERG N, RUBIN GJ (2020) The psychological impact of quarantine and how to reduce it: rapid review of the evidence. The Lancet. 2020; vol., 395(10227), p.912-920.

29. HUANG Y, ZHAO N (2020) Generalized anxiety disorder, depressive symptoms and sleep quality during COVID-19 outbreak in China: a webbased crosssectional survey. Psychiatry Research. 2020; 112954.

30. GUO Z, JIANG S, LI Z, CHEN S (2020) Metabolic Syndrome "Interacts" With COVID-19. BIOI. 2020; 1(4):168-177.

31. CHOCAIR PR et al. (2020) Covid-19 and Metabolic Syndrome. Rev Assoc Med Bras 2020; 66(7):871-87.

32. OZKAN O, KARACOBAN L, DONMEZ G, DEMIREL AH. The importance of preventing the metabolic syndrome pandemic after the COVID-19 outbreak. Turk J Sports Med. 2020; 55(3):256-8.

33. TAQUET M, LUCIANO S, GEDDES JR, HARRISON PJ (2021) Bidirection all associations between COVID-19 and psychiatric disorder: retrospective cohort studies of 62 354 COVID -19 cases in the USA. Lancet Psychiatry. 2021; vol. 8, p. 130-40.

34. De HERT M, CORRELL CHU, BOBES J, CETKOVICH-BAKMAS M, COHEN D, et al.(2011) Physical illness in patients with severe mental disorders. I. Prevalence, impact of medications and disparities in health care. World Psychiatry. 2011; 52-77.

35. AL-JABI SW (2021) Current global research landscape on COVID-19 and depressive disorders: Bibliometric and visualization analysis. World J Psychiatr. 2021; 11(6): 253-264.

36. WANG D, HU B, HU C, ZHU F, LIU X, ZHANG J, WANG B, XIANG H, CHENG Z, XIONG Y, ZHAO Y, LI Y, WANG X, PENG Z (2020) Clinical Characteristics of 138 Hospitalized Patients With 2019 Novel Coronavirus-Infected Pneumonia in Wuhan, China. JAMA. 2020; 323: 1061-1069.

37. IOB E, STEPTOE A, FANCOURT D (2020) Abuse, self-harm and suicidal ideation in the UK during the COVID-19 pandemic. The British Journal of Psychiatry. 2020; vol.217, no.4, p. 543-546.

38. SALARI N, HOSSEINIAN-FAR A, JALALI R, VAISI- RAYGANI A, RA-SOULPOOR S, MOHAMMADI M, KHALEDI-PAVEH B (2020) Prevalence of stress, anxiety, depression among the general population during the COVID-19 pandemic: a systematic review and metaanalysis.Globalization and Health. 2020; vol.16, no.1, p. 1-11.

39. GAO F, ZHENG KI, WANG XB, SUN QF, PAN KH, WANG TY, CHEN YP, TARGHER G, BYRNE CD, GEORGE J, ZHENG MH (2020) Obesity Is a Risk Factor for Greater COVID-19 Severity. Diabetes Care. 2020; 43 : e72-e74.

40. GIORGI G, LECCA L. I, ALESSIO F, FINSTAD G. L, BONDANINI G, LUL-LI L. G, MUCCI N (2020) COVID-19-related mental health effects in the workpla-ce: narrative review. International Journal of Environmental esearch and Public Health. 2020; vol.17, no. 21, p. 7857. 